\title{
Effect of different fertilization on spring cabbage (Brassica oleracea L. var. capitata) production and fertilizer use efficiencies
}

\author{
Zhibin $\mathrm{Guo}^{1}$, Chuanlong He${ }^{1,2 \#}$, Youhua $\mathrm{Ma}^{3}$, Hongbin $\mathrm{Zhu}^{1,2}$, Feng Liu ${ }^{1,2}$, Daozhong Wang ${ }^{1,2}$, \\ Li Sun ${ }^{3}$ \\ ${ }^{1}$ Soil and Fertilizer Research Institute, Anhui Academy of Agricultural Sciences, Hefei, China; \\ ${ }^{2}$ Key laboratory of Nutrient Cycling and Resources Environment, Anhui Province, Anhui Academy of Agricultural of Agricultural \\ Sciences, Hefei, China; \\ ${ }^{3}$ Resources and Environment College of Anhui Agriculture University, Hefei, China; ${ }^{\#}$ Corresponding Author: \\ hc160128@yahoo.com.cn
}

Received 23 May 2011; revised 13 July 2011; accepted 27 July 2011.

\begin{abstract}
Just after transplanting, the vegetable has difficulty in nutrients uptake. To explore the effect of different fertilization on spring cabbage (Brassica oleracea L. var. capitata) production and fertilizer use efficiencies, this experiment consisting of six treatments was implemented and divided into three groups: 1) no fertilizer (NF) and vegetable planting fertilizer (VPF); 2) conventional fertilizer (CF) and conventional fertilizer + vegetable planting fertilizer (CVPF); 3) reduced fertilizer application (RFA) and reduced fertilizer application + vegetable planting fertilizer (RVPF). The results of this experiment indicated that the yields of spring cabbage treated by VPF increased by $38.20 \%$ in VPF, $16.00 \%$ in CVPF and $20.40 \%$ in RVPF than their controls respectively. Additionally, the VPF helped improve the total and economic yields of the spring cabbage in all groups, and the economic benefits increased by $38.21 \%$ in VPF, $15.97 \%$ in CVPF and $20.42 \%$ in RVPF than their controls respectively. Finally, the VPF was of benefit to spring cabbage to exploit the soil nutrients and helped improve the chemical fertilizer use efficiencies. Therefore, it is an efficient, economical and ecological fertilization for vegetable production to apply chemical fertilizers in combination with VPF.
\end{abstract}

Keywords: Spring Cabbage; Fertilizer Use

*This research was supported by National Key Technology R\&D Program (2007BAD87B06) and President Youth Innovation Fund (11B1021).

\section{Efficiency}

\section{INTRODUCTION}

With an ever-growing population, China has to raise agricultural productivity in its limited and shrinking farmland to guarantee food. To increase the grain yield, a great amount of chemical fertilizers were applied to the agricultural system. Some study reported that the application of chemical fertilizers in China ranged from 225 to $375 \mathrm{~kg} \cdot \mathrm{ha}^{-1}$ [1]. Specially, the applied $\mathrm{N}$ fertilizer ranged from 400 to 600 or more than $600 \mathrm{~kg} \mathrm{~N} \cdot \mathrm{ha}^{-1} \cdot \mathrm{year}^{-1}$ in the agricultural regions of intensive farming in the Northern Plain of China [2,3]. For the greenhouse vegetable, the nitrogen fertilization was as high as 1000 $1500 \mathrm{~kg} \cdot \mathrm{ha}^{-1} \cdot$ year $^{-1}$ [2]. With the over-application of fertilizer, the non-point pollution has become seriously in China and other worldwide regions [4-7]. For example, over $50 \%$ of the wells in Northern Plain of China have been polluted which were related to the $\mathrm{NO}_{3}-\mathrm{N}$ leaching caused by excessive $\mathrm{N}$ fertilizer left in the cropland [6]. The coastal regions related about seven Provinces in China have already suffered seriously environmental pollution by NPS, which were primarily caused by the excessive application of synthetic fertilizer (particular nitrogen) and organic manure $[8,9]$.

It is urgent to strengthen the fertilizer management and improve the fertilizer use efficiency in agricultural system. Across the world, only about $30 \%-50 \%$ of the nitrogen fertilizer and $45 \%$ of the phosphorus fertilizer were taken up by crops $[10,11]$. Specially, the $\mathrm{N}$ and $\mathrm{P}$ fertilizer use efficiencies were much lower and only about $30 \%-35 \%$ and $10 \%-20 \%$ in China (Soil and fertilizer Institute CAAS, 1994). To secure a maximum grain yield, excessive fertilizer was applied by farmers 
and contributed to a higher production cost and worse soil structure through salinization and other forms of physical, chemical and biological degradation [12-14]. Therefore, a project called decrement and synergism of chemical fertilizers have been widely proposed for fertilizer management in China [15,16].

It is possible to maintain or increase the grain yield under limited fertilizer input. The most important step is to increase the fertilizer use efficiency and implement the decrement and synergism of chemical fertilizer project. Previous studies on limiting $\mathrm{N}$ fertilizer demonstrated that the yield of grain, vegetable and fruit could be maintained [17-19], and $\mathrm{N}$ fertilizer could be saved by $22 \%$ then reduced the runoff $\mathrm{N}$ and leaching $\mathrm{N}$ by $30 \%-40 \%$ and $32.3 \%$ respectively [20].

In some areas of intensive vegetable production, the fertilizer use efficiency was low shortly after transplanting [21]. Vegetable planting fertilizer (VPF), which consists of $\mathrm{Ca}\left(\mathrm{NO}_{3}\right)_{2}, \mathrm{CO}\left(\mathrm{NH}_{2}\right)_{2},\left(\mathrm{NH}_{4}\right)_{2} \mathrm{SO}_{4}, \mathrm{KH}_{2} \mathrm{PO}_{4}$, etc., is a new kind of fertilizer invented by Pro He in 2009 and is beneficial to spring cabbage (Brassica oleracea L. var. capitata) production and fertilizer use efficiency. To explore the effects of different fertilization on spring cabbage production and fertilizer use efficiencies, this experiment was designed. During the experiment, three groups consisting of six treatments were implemented: 1) no fertilizer (NF) and vegetable planting fertilizer (VPF); 2) conventional fertilizer $(\mathrm{CF})$ and conventional fertilizer + vegetable planting fertilizer (CVPF); 3) reduced fertilizer application (RFA) and reduced fertilizer application + vegetable planting fertilizer (RVPF). The aim of this research was to find a new regime of fertilization to improve the fertilizer use efficiencies and maintain the high production of vegetable

\section{MATERIALS AND METHODS}

\subsection{Site Description}

The experiment was conducted at Jiashen Country in the Juchao region of Chaohu city, Anhui Province, China $\left(31^{\circ} 16^{\prime}-32^{\prime} \mathrm{N}, 117^{\circ} 25^{\prime}-58^{\prime} \mathrm{E}\right.$ and $105 \mathrm{~m}$ above sea level). The annual mean temperature is $15.7-16.1^{\circ} \mathrm{C}$, ranging from $-7.0^{\circ} \mathrm{C}$ in January to $40^{\circ} \mathrm{C}$ in July. The annual mean precipitation is about $1200 \mathrm{~mm}$, and $28 \%$ $32 \%, 38 \%-44 \%, 18 \%-19 \%$ and $10 \%-11 \%$ of which occurred in March-May, June-August, September-October and December-February respectively. The average annual potential evaporation is about $1500 \mathrm{~mm}$. The soil is yellow brown earth with $15.0 \mathrm{~g} \cdot \mathrm{kg}^{-1}$ soil organic matter, $71.2 \mathrm{mg} \cdot \mathrm{kg}^{-1}$ available phosphorus and $261.2 \mathrm{mg} \cdot \mathrm{kg}^{-1}$ available potassium.

\subsection{Experimental Design}

The experiment was implemented from $26^{\text {th }}$ February
2009 to $9^{\text {th }}$ May 2009 and divided into three groups consisting of six treatments: 1) no fertilizer (NF); 2) vegetable planting fertilizer (VPF); 3) conventional fertilizer $(\mathrm{CF})$; 4) conventional fertilizer + vegetable planting fertilizer (CVPF); 5) reduced fertilizer application (RFA); 6) reduced fertilizer application + vegetable planting fertilizer (RVPF). In CF，525 kg.ha ${ }^{-1}$ carbamide and 750 $\mathrm{kg} \cdot \mathrm{ha}^{-1}$ NPK (N20-P20-K20) synthetic fertilizer were applied as base fertilizer and $225 \mathrm{~kg} \cdot \mathrm{ha}^{-1}, 225 \mathrm{~kg} \cdot \mathrm{ha}^{-1}$ and $300 \mathrm{~kg} \cdot \mathrm{ha}^{-1} \mathrm{NH}_{4} \mathrm{HCO}_{3}$ were used for topdressing in the seedling stage, rosette stage and head formation period of spring cabbage respectively. The amount of chemical fertilizer applied in RFA was $70 \%$ of $\mathrm{CF}$ across the spring cabbage growth. In all VPF treatments, the spring cabbage was treated by $500 \mathrm{ml}$ of $0.112 \%$ vegetable planting fertilizer solution per individual. In the experimental site, the crop system was spring cabbage/corn inter-planting, in which the conventional fertilizer was implemented for spring cabbage growth and no fertilizer in corn growth. Each plot, about $15 \mathrm{~m}^{3}$, was replicated three times in a completely randomized design.

\subsection{Sampling and Analysis}

Plant samples were taken randomly in the head formation period and harvest time of spring cabbage with three replicates and then divided into two sub-samples: one was calculated for productivity of spring cabbage and the other one was dried in an oven at $105^{\circ} \mathrm{C}$ for $1 \mathrm{~h}$ and then at $70^{\circ} \mathrm{C}$ for a minimum of $72 \mathrm{~h}$ for nutrient testing. Plant nutrient content was analyzed using the methods outlined by Nanjing Agriculture University (1996). After a $\mathrm{H}_{2} \mathrm{O}_{2}-\mathrm{H}_{2} \mathrm{SO}_{4}$ digest, the plant nitrogen, phosphorus and potassium were tested by Kjeldahl digestion method, colorimetric method (using $\mathrm{HClO}_{4}$ $\mathrm{H}_{2} \mathrm{SO}_{4}$ ) and flame photometry method [22] respectively.

\subsection{Statistical Analysis}

Differences among treatments on the productivity and nutrients of spring cabbage were analyzed by ANOVA using SAS 9.1.3. All graphs were plotted by Origin 7.5.

\section{RESULTS AND DISCUSSION}

\subsection{Yields of Spring Cabbage}

To secure a maximum yield, a large number of chemical fertilizers were used by vegetable farmers in the areas of highly intensive vegetable production, especially $\mathrm{N}$ fertilizer. In this experiment, the yields of spring cabbage increased significantly after fertilizing. Compared to NF, the spring cabbage yields in all fertilizing treatments increased significantly $(p<0.05)$ both in the head formation period and harvest time (Table 1 and Figure 
Table 1. N, P and K fertilizer, total and economic yield of spring cabbage in no fertilizer (NF), vegetable planting fertilizer (VPF), conventional fertilizer $(\mathrm{CF})$, conventional fertilizer + vegetable planting fertilizer (CVPF), reduced fertilizer application (RFA) and reduced fertilizer application + vegetable planting fertilizer (RVPF) during the experiment.

\begin{tabular}{ccccccc}
\hline Treatments & $\begin{array}{c}\mathrm{N} \\
\text { fertilizer } \\
\left(\mathrm{kg} \cdot \mathrm{ha}^{-1}\right)\end{array}$ & $\begin{array}{c}\mathrm{P} \\
\text { fertilizer } \\
\left(\mathrm{kg} \cdot \mathrm{ha}^{-1}\right)\end{array}$ & $\begin{array}{c}\mathrm{K} \\
\text { fertilizer } \\
\left(\mathrm{kg} \cdot \mathrm{ha}^{-1}\right)\end{array}$ & $\begin{array}{c}\text { Total Yield } \\
\left(\mathrm{kg} \cdot \mathrm{ha}^{-2}\right)\end{array}$ & $\begin{array}{c}\text { Economic Yield** } \\
\left(\mathrm{kg} \cdot \mathrm{ha}^{-1}\right)\end{array}$ & $\begin{array}{c}\text { Economic Ratios } \\
(\%)\end{array}$ \\
\hline $\mathrm{NF}$ & 0 & 0 & 0 & $56847 \pm 2076 \mathrm{~d}$ & $30306 \pm 1107 \mathrm{~d}$ & $53.31 \mathrm{c}$ \\
$\mathrm{VPF}$ & 4.8 & 3 & 2 & $64824 \pm 1555 \mathrm{c}$ & $41886 \pm 1005 \mathrm{c}$ & $64.62 \mathrm{~b}$ \\
$\mathrm{CF}$ & 481.5 & 112.5 & 112.5 & $81652 \pm 2208 \mathrm{ab}$ & $52854 \pm 1429 \mathrm{~b}$ & $64.73 \mathrm{~b}$ \\
CVPF & 486.3 & 115.5 & 114.5 & $83833 \pm 1362 \mathrm{a}$ & $61293 \pm 864 \mathrm{a}$ & $73.12 \mathrm{a}$ \\
RFA & 337.1 & 78.8 & 78.8 & $77715 \pm 1732 \mathrm{~b}$ & $49878 \pm 1102 \mathrm{~b}$ & $64.18 \mathrm{~b}$ \\
RVPF & 341.9 & 81.8 & 80.8 & $83347 \pm 1854 \mathrm{a}$ & $60065 \pm 1233 \mathrm{a}$ & $72.07 \mathrm{a}$ \\
\hline
\end{tabular}

1). In all groups, the yields of spring cabbage treated by VPF were much higher than their controls, especially CVPF and RVPF (Figure 1) which indicated that the combination of VPF and chemical fertilizer performed better than using the chemical fertilizer alone duced fertilizer application and reduced fertilizer application + vegetable planting fertilizer respectively. Error bars represent standard errors $(n=3)$.

\subsection{Economic Benefit of Spring Cabbage}

During the vegetable production, the overuse of fertilizer decreased the income of vegetable farmers by increasing the production cost and reducing crop yield caused by soil degradation $[12,14,23]$. In this experiment,

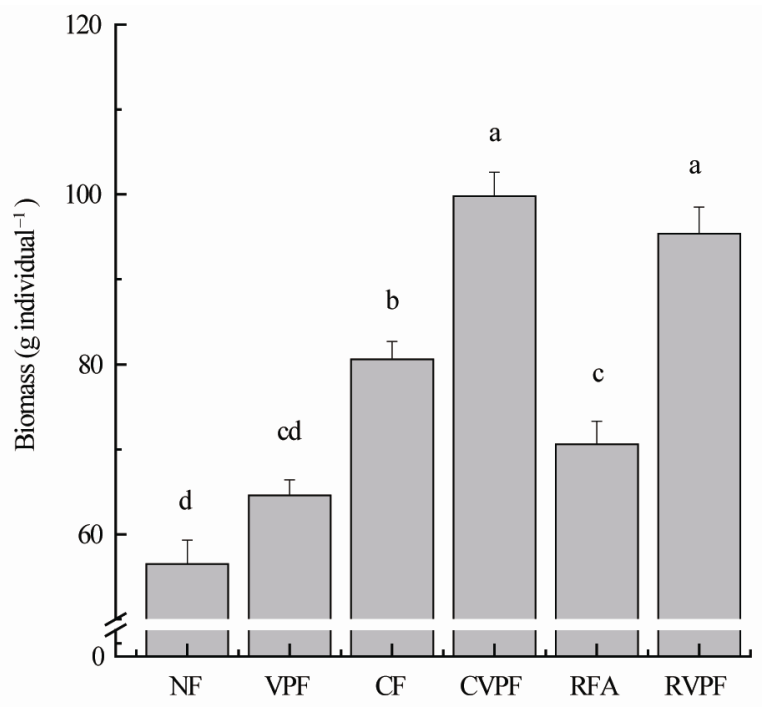

Figure 1. Effect of different fertilization on the biomass in the head formation period of spring cabbage. The NF, VPF, CF, CVPF, RFA and RVPF represented no fertilizer, vegetable planting fertilizer, conventional fertilizer, conventional fertilizer + vegetable plant fertilizer, reduced fertilizer application and reduced fertilizer application + vegetable planting fertilizer respectively. Error bars represent standard errors $(n=3)$. the costs of fertilizers were $225.00,5015.00,5086.00$, 3510.00 and 3582.00 Yuan $\cdot \mathrm{hm}^{-2}$ in VPF, CF,

CVPF, RFA and RVPF respectively (the prices of N, P and $\mathrm{K}$ fertilizers were 6.25 RMB Yuan $\mathrm{kg}^{-1}, 7.5 \mathrm{RMB}$ Yuan $\cdot \mathrm{kg}^{-1}$ and 9.17 RMB Yuan $\cdot \mathrm{kg}^{-1}$ respectively). From Table 1, it is obviously to find that the economic yield of spring cabbage treated by VPF increased significantly. Across the experiment, the output value with different fertilization was obviously higher than no fertilizing due to the high vegetable yield (Figure 2). In contrast to NF, the output value increased by $38.21 \%$ in VPF, $74.40 \%$ in CF, $102.25 \%$ in CVPF, $64.58 \%$ in RFA and $98.20 \%$ in CRFA respectively. Moreover, the output value of spring cabbage treated by VPF was significantly $(p<0.05)$ higher than their controls in each groups.

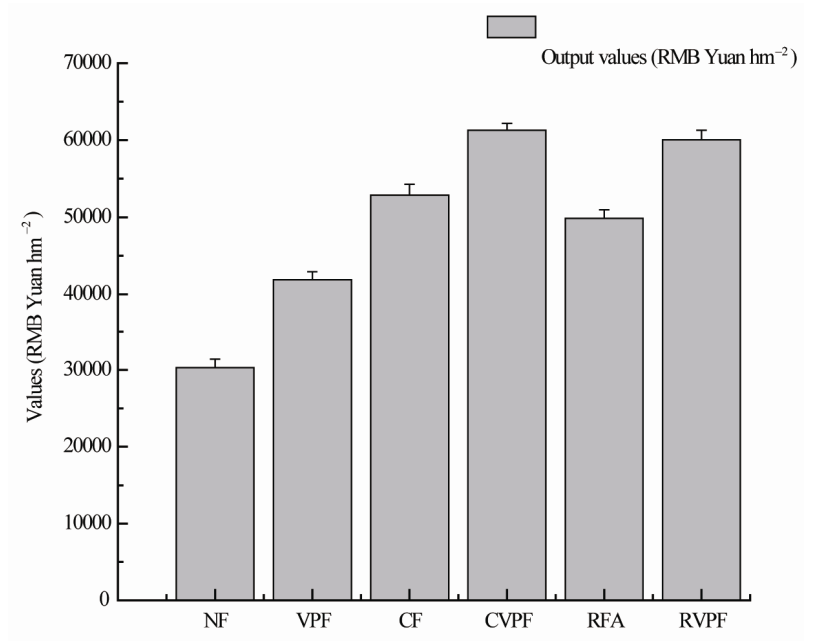

Figure 2. The output values of spring cabbage in the experiment. The NF, VPF, CF, CVPF, RFA and RVPF represented no fertilizer, vegetable planting fertilizer, conventional fertilizer, conventional fertilizer + vegetable plant fertilizer, reduced fertilizer application and reduced fertilizer application + vegetable planting fertilizer respectively. The price of spring cabbage was $1.0 \mathrm{RMB}$ Yuan $\mathrm{kg}^{-1}$ (the RMB Yuan is the Chinese Currency unit). Error bars represent standard errors $(n=3)$. 


\subsection{Nutrient Content of Spring Cabbage and the Fertilizer Use Efficiency}

During the past decades, the land area for vegetable production in China has increased significantly, ranging from 3.2 to 17.6 million hectares from 1984 to 2004 (China Statistical Year book, 2005). To maximize the yield and output value of vegetable production, the fertilizer input increased significantly. For example, the nitrogen and phosphorus fertilizers using globally increased 7- and 3.5-fold from 1960 to 1995 and both were expected to increase another 3-fold by 2050 if the fertilizer use efficiency was constant [24,25]. Past study indicated that the $\mathrm{N}, \mathrm{P}$ and $\mathrm{K}$ fertilizer use efficiencies were only about $30 \%-35 \%, 10 \%-20 \%$ and $40 \%-50 \%$ respectively in China (Soil and fertilizer Institute CAAS, 1994). Therefore, a great amount of NPS fertilizers was lost and then caused seriously environmental damage $[20,26,27]$. In this experiment, it helped improve the fertilizer use efficiency and maintain the quality of spring cabbage that combination of chemical fertilizer and VPF (Tables 2 and 3). During the spring cabbage production, the VPF helped decrease the chemical fertilizer and increase the economic income of vegetable farmers. In $\mathrm{CF}$, the ratio of spring cabbage output value: fertilizer cost was 10.54; Compared to $\mathrm{CF}$, the ratio of output value to fertilizer cost increased significantly ( $p<$ 0.05 ) and reached to 12.05 in CVPF, 14.21 in RFA and 16.77 in RVPF respectively.

In agricultural system, nitrogen is an essential, limited nutrient for crop growth. However, over-application of $\mathrm{N}$ fertilizer could contribute to agricultural non-point source pollution [6,7]. In some areas of intensive vegetable production, the level of applied nitrogen fertilizer was commonly double the recommended level [28] then over half of the nitrogen fertilizer was lost from the

Table 2. N, P and K of spring cabbage in no fertilizer (NF), vegetable planting fertilizer (VPF), conventional fertilizer (CF), conventional fertilizer + vegetable planting fertilizer (CVPF), reduced fertilizer application (RFA) and reduced fertilizer application + vegetable planting fertilizer (RVPF) during the experiment.

\begin{tabular}{cccc}
\hline Treatments & $\begin{array}{c}\mathrm{N} \\
\left(\mathrm{g} \mathrm{kg}^{-1}\right)\end{array}$ & $\begin{array}{c}\mathrm{P} \\
\left(\mathrm{g} \mathrm{kg}^{-1}\right)\end{array}$ & $\begin{array}{c}\mathrm{K} \\
\left(\mathrm{g} \mathrm{kg}^{-1}\right)\end{array}$ \\
\hline $\mathrm{NF}$ & $32.6 \pm 1.8 \mathrm{a}$ & $4.6 \pm 0.2 \mathrm{a}$ & $13.9 \pm 0.4 \mathrm{ab}$ \\
VPF & $30.6 \pm 2.1 \mathrm{a}$ & $4.6 \pm 0.3 \mathrm{a}$ & $13.0 \pm 0.4 \mathrm{~b}$ \\
CF & $32.5 \pm 0.9 \mathrm{a}$ & $4.6 \pm 0.2 \mathrm{a}$ & $14.8 \pm 0.3 \mathrm{a}$ \\
CVPF & $32.3 \pm 1.2 \mathrm{a}$ & $4.6 \pm 0.3 \mathrm{a}$ & $15.0 \pm 0.2 \mathrm{a}$ \\
RFA & $32.3 \pm 1.2 \mathrm{a}$ & $4.5 \pm 0.1 \mathrm{a}$ & $14.3 \pm 0.4 \mathrm{ab}$ \\
RVPF & $31.8 \pm 1.8 \mathrm{a}$ & $4.5 \pm 0.2 \mathrm{a}$ & $14.4 \pm 0.3 \mathrm{a}$ \\
\hline
\end{tabular}

Table 3. Fertilizer use efficiencies of spring cabbage treated by different fertilization.

\begin{tabular}{cccc}
\hline \multirow{2}{*}{ Treatments } & \multicolumn{3}{c}{ Fertilizer using efficiency } \\
\cline { 2 - 4 } & $\mathrm{N}(\%)$ & $\mathrm{P}(\%)$ & $\mathrm{K}(\%)$ \\
\hline VPF & $148.6 \pm 1.7 \mathrm{a}$ & $153.5 \pm 2.7 \mathrm{a}$ & $180.5 \pm 3.1 \mathrm{a}$ \\
CF & $9.3 \pm 0.3 \mathrm{c}$ & $12.7 \pm 0.5 \mathrm{c}$ & $24.9 \pm 0.6 \mathrm{c}$ \\
CVPF & $9.8 \pm 0.1 \mathrm{c}$ & $13.2 \pm 0.4 \mathrm{c}$ & $27.3 \pm 1.2 \mathrm{c}$ \\
RFA & $10.8 \pm 0.6 \mathrm{c}$ & $13.9 \pm 0.4 \mathrm{c}$ & $27.2 \pm 1.3 \mathrm{c}$ \\
RVPF & $12.9 \pm 0.4 \mathrm{~b}$ & $17.8 \pm 0.3 \mathrm{~b}$ & $34.0 \pm 1.3 \mathrm{~b}$ \\
\hline
\end{tabular}

$\mathrm{VPF}=$ vegetable planting fertilizer, $\mathrm{CF}=$ conventional fertilizer, $\mathrm{CVPF}=$ conventional fertilizer + vegetable planting fertilizer, RFA = reduced fertilizer application and RVPF $=$ reduced fertilizer application + vegetable planting fertilizer. Values within a column followed by the same lower case did not differ at $p<0.05$ for the specific variable. Error bars represent standard errors $(n=3)$.

cropland as gases or in drainage or runoff water before it could benefit crop growth [2]. To reduce $\mathrm{NO}_{3}-\mathrm{N}$ leaching and increase $\mathrm{N}$ use efficiency, it is important to strengthen the management of $\mathrm{N}$ inputs [12,13]. From Table 3, it's easy to find that the nitrogen fertilizer use efficiency increased significantly after combination of VPF and chemical fertilizer or VPF applied alone. Among all the treatments, the $\mathrm{N}$ fertilizer use efficiency of VPF was the highest and reached to $148.6 \%$, which suggested more nitrogen stored in the soil was exploited by spring cabbage beside vegetable planting fertilizer. Additionally, VPF also helped improve the chemical fertilizer use efficiency. In each group, the fertilizer use efficiencies of CVPF and RVPF were much higher than their controls. Similarly, the VPF helped improve the P and $\mathrm{K}$ fertilizer use efficiencies across the vegetable production.

\section{CONCLUSIONS}

In the experiment, the vegetable planting fertilizer performed better than the traditional fertilizers. In the head formation period and harvest time of spring cabbage, it helped the vegetable exploit more soil nutrients for its growth. Moreover, the vegetable planting fertilizer combined with chemical fertilizers was beneficial to improve the chemical fertilizer use efficiencies with maintenance of vegetable yield, which contributed to low fertilizer cost and increase the income of farmers. Therefore, the vegetable planting fertilizer is an efficient, economic and ecological fertilizer for vegetable production after combination with chemical fertilizer. More research needed to be done to learn how the vegetable planting fertilizer improved the spring cabbage ability to exploit soil nutrients during its growth.

\section{ACKNOWLEDGEMENTS}

The authors thank bachelors Jing Zhao, Dan Ma and Zhengfei Feng 
for their helps during the experiment.

\section{REFERENCES}

[1] Zeng, X.B. and Li, J.M. (2004) Fertilizer application and its effect on grain production in different counties of China. Scientia Agricultura Sinica, 37, 387-392.

[2] Zhu, Z.L. and Chen, D.L. (2002) Nitrogen fertilizer use in China-contributions to food production, impacts on the environment and best management strategies. Nutrient Cycling in Agroecosystems, 63, 117-127.

doi:10.1023/A:1021107026067

[3] Liu, X. and Ju, X. (2003) Nitrogen dynamics and budgets in a winter wheat-maize cropping system in the North China Plain. Field Crops Research, 83, 111-124. doi:10.1016/S0378-4290(03)00068-6

[4] Newbould, P. (1989) The use of nitrogen fertilizer in agriculture. Where do we go practically and ecologically? Plant and Soil, 11, 297-311. doi:10.1007/BF02202596

[5] Follett, R.F. (1989) Nitrogen management and ground water protection. Elsevier Science Publishers, Amsterdam.

[6] Zhang, W.L., Tian, Z.X., Zhang, N. and Li, X.Q. (1996) Nitrate pollution of groundwater in Northern China. Agriculture. Ecosystems and Environment, 59, 223-231. doi:10.1016/0167-8809(96)01052-3

[7] Delgado, J.A. (2002) Quantifying the loss mechanisms of nitrogen. Journal of soil water conservation, 57, 389398.

[8] Ju, X.T., Liu, X.J., Zhang, F.S. and Roelcke, M. (2004) Nitrogen fertilization, soil nitrate accumulation, and policy recommendations in several agricultural regions of China. Ambio: A Journal of the Human Environment, 33, 300-305.

[9] Shen, R.P., Sun, B. and Zhao, Q.G. (2005) Spatial and temporal variability of $\mathrm{N}, \mathrm{P}$ and $\mathrm{K}$ balances for agroecosystems in China. Pedosphere, 15, 347-355.

[10] Cassman, K.G., Dobermann, A. and Walters, D. (2002) Agroecosystems, nitrogen-use efficiency, and nitrogen management. AMBIO, 31, 132-140.

[11] Smil, V. (2000) Phosphorus in the environment: natural flows and human interferences. Annual Review of Energy Environment, 25, 53-88. doi:10.1146/annurev.energy.25.1.53

[12] Khosla, R., Fleming, K., Delgado, J.A., Shaver, T. and Westfall, D. (2002) Use of site specific management zones to improve nitrogen management for precision agriculture. Journal of Soil Water Conservation, 57, 513518.

[13] Delgado, J.A., Khosla, R., Bausch, W.C., Westfall, D.G., and Inman, D. (2005) Nitrogen fertilizer management based on site specific management zones reduce potential for nitrate leaching. Journal of Soil Water Conservation, 60, 402-410.

[14] Li, X.X., Hu, C.S., Delgado, J.A., Zhang, Y.M. and Ouyang, Z.Y. (2007) Increased nitrogen use efficiences as a key mitigation alternative to reduce nitrate leaching in North China Plain. Agricultural Water Management, 89, 137-147. doi:10.1016/j.agwat.2006.12.012

[15] Xie, W.F. and Ye, H.H. (2007) Field experiment on dec- rement and synergism of Chemical fertilizer. Journal of Anhui Agriculture Science, 35, 6868-6875.

[16] Zhang, Y. Zh., Wang, K.R., Liu, J.P., Huang, Zh.N., Zeng, X. and Zhou, Sh.Q. (2006) Demonstrations and studies on techniques for rice quality security control. Crop Research, 4, 287-296 (in Chinese).

[17] Xiao, G.X., Li, C.J., Wang, L. and Cheng, G.H. (2003) Study of reducing the amount of using fertilizer in corn growth. Soils and Fertilizers, 6, 37-40 (in Chinese).

[18] Yao, C.X., Chen, Z.L., Qiu, Q., Huang, Y.H., Yin, J., Zhang, J.X., Li, C.H. and Mao, G.F. (2005) Influence of nitrogen fertilizer reduction amount on watermelon yield and quality under canopy cultivation. Acta Agriculturae Boreali-Sinica, 20, 76-79 (in Chinese).

[19] Jiang, Q., Yu, H.J. and Shi, Z.Y. (2006) Effective ways of reducing chemical $\mathrm{N}$ fertilizer application in rice growth. Journal of Shanghai Jiaotong University (Agricultural Science), 24, 452-455 (in Chinese).

[20] Zhang, G., Wang, D.J. and Chen, X.M. (2008) Efffects of reduced fertilizer application on environmental of paddy field. Chinese Journal of Ecoagriculture, 16, 327-330 (in Chinese). doi:10.3724/SP.J.1011.2008.00327

[21] Wang, G.H., Dobermann, A., Witt, C., Sun, Q.Z. and Fu, R.X. (2001) Performance of site-specific nutrient management for irrigated rice in southeast China. Agronomy Journal, 90, 178-185.

[22] Parkinson, J.A. and Allen, S.E. (1975) A wet oxidation process suitable for the determination of nitrogen and mineral nutrients in biological material. Communications in Soil Science and Plant Analysis, 6, 1-11. doi:10.1080/00103627509366539

[23] Buresh, R., Peng, S., Huang, J., Yang, J., Wang, G., Zhong, X. and Zou, Y. (2004) Rice systems in China with high nitrogen inputs. In: Mosier, A.R., Syers, J.K. and Freney, J.R., Eds., Agriculture and the Nitrogen Cycle: Assessing the Impacts of Fertilizer use on Food Production and the Environment, Island Press, Washington, 143153.

[24] Tilman, D., Reich, P.B., Knops, J., Wedin, D., Mielke, T. and Lehman, C. (2001) Diversity and productivity in a long-term grassland experiment. Science, 294, 843-845. doi:10.1126/science.1060391

[25] Cassman, K.G. and Pingali, P.L. (1995) Intensification of irrigated rice systems: Learning from the past to meet future challenges. GeoJournal, 35, 299-305. doi:10.1007/BF00989137

[26] Tong, Y.N. (2001) Nitrogen fertilizer and environment. In: Feng, F., Ed., Study on Plant Nutrition-Progress and Prospect, China Agricultural University Press, Beijing, 207-215 (in Chinese).

[27] Mosier, A.R. and Zhu, Z.L. (2000) Changes in patterns of fertilizer nitrogen use in Asia and its consequences for $\mathrm{N}_{2} \mathrm{O}$ emissions from agricultural systems. Nutrient Cycling in Agroecosystems, 57, 107-117. doi:10.1023/A:1009716505244

[28] Zhang, W.L., Wu, S.X., Ji, H.J. and Kolbe, H. (2004) Estimation of agricultural non-point source pollution in China and the alleviating strategies I Estimation of agricultural non-point source pollution in China in early 21 century. Scientia Agricutura Sinica, 36, 1008-1017. 